\title{
Dementia after stroke: Baseline frequency, risks, and clinical features in a hospitalized cohort
}

\author{
T.K. Tatemichi, MD; D.W. Desmond, PhD; R. Mayeux, MD; M. Paik, PhD; Y. Stern, PhD; M. Sano, PhD; \\ R.H. Remien, PhD; J.B.W. Williams, DSW; J.P. Mohr, MD; W.A. Hauser, MD; and M. Figueroa, MD
}

\begin{abstract}
Article abstract-We determined the frequency of dementia in a cohort of 251 patients aged $\geq 60$ years hospitalized with acute ischemic stroke, based on examinations performed 3 months after stroke onset. Using modified DSM-III-R criteria, we found dementia in 66 patients $(26.3 \%)$. Diagnostic agreement among raters was excellent $(\mathrm{kappa}=0.96)$. In a control sample of 249 stroke-free subjects recruited from the community and matched by age, we found dementia in eight subjects (3.2\%). Using a logistic regression model to estimate the risk of dementia associated with stroke in the combined samples, the odds ratio (OR) for stroke patients compared with control subjects was $9.4(p<0.001)$. Advancing age and fewer years of education were significant, independent correlates of dementia, with a trend evident for race (non-white versus white). Confining the analysis to subjects residing in the Washington Heights-Inwood community of northern Manhattan, the OR was $10.3(p<0.001)$ with significant age and race effects. We conclude that ischemic stroke significantly increases the risk of dementia, with independent contributions by age, education, and race.
\end{abstract}

NEUROLOGY 1992;42:1185-1193

The risk of dementia following ischemic stroke is incompletely understood. Most previous studies have focused on selected or consecutively encountered patients with dementia rather than investigating dementia in stroke cohorts. Depending on the specific sample examined and the diagnostic criteria used in such studies, it has been argued that vascular dementia is either overdiagnosed ${ }^{1}$ or underdiagnosed. ${ }^{2}$ In autopsy series, stroke accounts for 20 to $25 \%$ of all dementia cases, while another 10 to $15 \%$ are explained by a combination of vascular disease and Alzheimer's disease (AD).$^{3,4}$ In clinical series, but more often in population-based studies in the United States, ${ }^{5,6}$ the proportion of dementia directly attributable to stroke has been reported to be even lower, approximately 10 to $15 \%$ overall. ${ }^{7}$

To better understand the relationship between stroke and dementia, however, the question should be refocused to inquire: does cerebrovascular disease increase the risk of dementia, and if so, to what extent? This approach requires the prospective study of a stroke cohort, compared with a reference sample, using well-defined diagnostic criteria based on findings from neuropsychological and functional examinations. Using these methods, we report the results of the first phase of such a study in a cohort of elderly patients hospitalized for acute ischemic stroke.

Methods. Subject selection. Subjects for this study were recruited among patients admitted consecutively to Columbia-Presbyterian Medical Center between September 1, 1988 and December 31, 1990 with acute ischemic stroke occurring within the previous 30 days. Eligible patients were 60 years of age or older, of either sex, with the diagnosis of ischemic stroke confirmed by $\mathrm{CT}$ of the brain (normal or focal, low-density lesion) performed within 1 week of symptom onset. An elderly sample was selected to focus on a group presumably at high risk for dementia. Patients were excluded when certain clinical features prevented a reliable assessment of dementia, such as a severe aphasia (ie, a score of $<3$ on the Aphasia Severity Rating Scale ${ }^{8}$ from the Boston Diagnostic Aphasia Examination [BDAE]), persistent impairment in consciousness from any cause, or primary language other than English or Spanish. Some patients who were too impaired cognitively (or untestable) shortly after stroke onset but were otherwise eligible were enrolled and given initial hospital examinations, with the expectation that sufficient functional recovery might occur by 3 months when neuropsychological testing would be administered. Additional exclusions were the

From the Departments of Neurology (Drs. Tatemichi, Desmond, Mayeux, Stern, Sano, Williams, Mohr, Hauser, and Figueroa) and Psychiatry (Drs. Mayeux, Stern, Remien, and Williams), the Division of Biostatistics (Dr. Paik), and the Gertrude H. Sergievsky Center (Drs. Mayeux, Hauser, and Stern), Columbia University, College of Physicians and Surgeons, New York, NY.

Supported in part by Grants R01-NS26179 and P01-AG07232 from the National Institutes of Health.

Presented in part at the 43rd annual meeting of the American Academy of Neurology, Boston, MA, April 1991.

Received September 23, 1991. Accepted for publication in final form November 12, 1991.

Address correspondence and reprint requests to Dr. T.K. Tatemichi, Stroke and Aging Research Project, Neurological Institute, 710 West 168 th Street, New York, NY 10032. 
presence of a concomitant primary cerebral disorder (eg, Parkinson's disease) or severe medical comorbidity (eg, terminal cancer) limiting survival over the planned follow-up period of 5 years. Informed consent was obtained from the patient, or next-of-kin when appropriate (eg, among demented patients).

To maximize case ascertainment, a daily survey of admission sources to the medical center was conducted during the 28-month period of the baseline phase. This surveillance identified a total of 1,511 admissions for acute cerebrovascular disease, of whom 221 were for transient ischemic attack (14.6\%) and 371 for cerebral hemorrhage (24.6\%), diagnoses not eligible for this study. Among the 919 patients with ischemic stroke $(60.8 \%)$, 261 were below 60 years of age. Therefore, potential study subjects were recruited among the remaining 658 patients. From this group, $222(33.7 \%)$ were found unsuitable for dementia studies because of severe aphasia or clouded consciousness precluding dementia assessment $(\mathrm{n}=131)$, coexisting cerebral or severe medical disorder $(n=81)$, or primary language not English or Spanish ( $n=10)$. Among the 436 who could be adequately tested, $297(68.1 \%)$ were finally enrolled during hospitalization. Reasons for nonenrollment of the remaining patients included refusal by the patient or primary physician $(21.3 \%)$, discharge before 7 days $(6.4 \%)$, or planned emigration beyond 50 miles of the medical center after discharge from the hospital (3.4\%).

A control group was also enrolled as a reference sample and was composed of 249 subjects over 60 years of age without historical or clinical examination evidence of stroke. Aside from cerebrovascular disease assessed clinically, the presence of vascular risk factors and other medical or neurologic disorders (including dementia) was not exclusionary, in an attempt to assemble a representative comparison sample from the community. We elected not to recruit hospitalized controls because we planned to use the reference group for longitudinal comparisons as well, a purpose better served by a community sample. Whenever available, we attempted to recruit the spouse of a stroke subject (17.3\%). The remaining controls were obtained either by probability sampling using a roster of neighborhood residents obtained from Medicare files and a commercial list $(53.0 \%)$, or from neighborhood volunteers $(29.7 \%)$ who came to our attention by community advertising or word-of-mouth. As a group, we attempted to match controls to the stroke subjects by age.

General clinical assessment. For stroke subjects, the initial examinations were planned during hospitalization approximately 7 to 10 days after stroke onset; for those admitted beyond that period, examinations occurred approximately 30 days from onset. Each subject underwent a structured medical and neurologic history, and a neurologic examination by a vascular neurologist (T.K.T., J.P.M., M.F.) with specific attention to stroke features, similar to the method of the Stroke Data Bank (SDB). ${ }^{9}$ Patients were also rated on the SDB Stroke Severity Scale (maximum $=12$ ), a combined summary of neurologic deficits and disability. ${ }^{9}$ The following interviews and examinations were administered by a trained nurse or research assistant: the Folstein Mini-Mental State Examination (MMSE) (maximum $=30)^{10}$; Barthel Index $(\text { maximum }=100)^{11}$; Blessed Functional Activity Scale (BFAS) (maximum $=17$ ), ${ }^{12}$ which was scored to reflect function in the 12 months before stroke onset; the sixitem version of the Orientation-Memory-Concentration test (Short Blessed) (maximum $=28)^{13}$; and a structured risk-factor questionnaire. Whenever possible, historical details were confirmed by a knowledgeable informant, with a special view toward establishing whether or not functional deficits were present before stroke onset. Demographic information was also collected, with specific attention to ethnic background, using the census bureau's method of self-assignment, which allowed classification into four main groups: white, non-Hispanic; black, non-Hispanic; Hispanic; and other.

Neuropsychological assessment. Approximately 3 months after stroke onset (designated as time 0 or baseline), patients were given a battery of neuropsychological tests developed for the purpose of diagnosing dementia in a bilingual (English and Spanish), multi-ethnic, elderly population ${ }^{14}$ as part of a broader epidemiologic study of dementia involving the Washington Heights-Inwood community surrounding the medical center. ${ }^{15}$ We chose an interval of 3 months following stroke onset for neuropsychological testing to allow sufficient time for the acute stroke effects to subside. ${ }^{16,17}$ Testing was conducted in either English or Spanish, depending on the preferred language of the subject (usually the language spoken at home). Cognitive functions assessed by this battery included the following: verbal memory (Selective Reminding Test ${ }^{18}$ ); visual memory (recognition task on the Benton Visual Retention Test $[\mathrm{BVRT}]^{19}$ ); orientation (orientation items from the MMSE ${ }^{10}$ ); language ability including naming (selected items from the Boston Naming Test ${ }^{20}$ ), verbal fluency (Controlled Word Association Test $^{21}$ and the category fluency subtest of the $\mathrm{BDAE}^{8}$ ), comprehension (first six items of the complex ideational materials subtest of the $\mathrm{BDAE}^{8}$ ), and repetition (high-frequency items from the $\mathrm{BDAE}^{8}$ ); visuospatial ability (five items selected from the Rosen Drawing Test ${ }^{22}$ and the matching task of the BVRT); abstract reasoning (similarities subtest of WAIS-R ${ }^{23}$ and the nonverbal similarities subtest of the Mattis Dementia Rating Scale $^{24}$ ); and attention (target detection tasks ${ }^{25}$ ).

Psychiatric assessment. A structured interview for psychiatric symptoms and disorders was administered by trained research assistants and consisted of the Hamilton Depression Rating Scale (17-item HDRS) (maximum $=57)^{26}$ and a modified version of the Structured Clinical Interview for DSM-III-R. ${ }^{27}$ These interviews were supervised and the results reviewed by clinicians experienced in psychiatric diagnoses (R.M., J.B.W.). The disorders screened included major depression (DSM-III-R), psychosis, and alcohol dependency.

Follow-up procedures. Interval neurologic and medical histories, including a medication history, were obtained, with particular attention to recurrent ischemic events. Current functional status was assessed with the Barthel and Blessed functional interviews. In the majority of cases, functional rating (BFAS) was based on information provided by a surrogate whom we considered reliable (eg, family member or home attendant). Control subjects underwent an identical examination procedure. Repeat examinations are planned for stroke and control subjects annually as part of the incidence phase of the study.

Diagnostic criteria for dementia and dementia subtypes. Using criteria modified from the DSM-III-R, ${ }^{28}$ we determined the presence or absence of dementia based on information from neurologic, neuropsychological, psychiatric, and functional examinations at the 3-month (baseline) visit. Information was reviewed at a diagnostic conference including the examining neurologist and at least two neuropsychological raters experienced in the diagno- 
sis of dementias (Y.S., M.S., R.M.); if any two raters disagreed, the judgment of the third rater was sought and consensus achieved. Agreement on the diagnosis of dementia was excellent ${ }^{29}$ with a kappa of 0.96 , based on independent judgments in a sample of 63 subjects. The findings reported here represent the consensus diagnoses resulting from the case conferences.

Our research criteria for dementia required the presence of memory impairment and two or more deficits in other cognitive functions (excluding attention, since many stroke subjects with hemiparesis are unable to perform those tasks) with predetermined cutoff scores for each of the subtests developed from pilot data. ${ }^{14}$ In evaluating memory deficits, special considerations were applied to account for focal stroke effects. For example, if there was a language deficit due to a left hemisphere stroke, impairment in nonverbal memory was required; if either verbal or nonverbal memory could not be assessed because of stroke-related language and visuospatial defects, then the patient was considered untestable at 3 months, with retesting planned 1 year later; if memory impairment or other deficits were directly attributable to the focal brain injury (eg, mesial temporal lobe), then the deficit was considered in applying the criteria for dementia, but such patients were given special subtype designations (see below). Moreover, consistent with DSM-III-R, functional impairment resulting from cognitive deficits, apart from any physical effects resulting from the stroke, was an additional diagnostic requirement using information from BFAS and other sources.

To summarize the overall severity of dementia, we rated subjects on the Clinical Dementia Rating Scale $(\mathrm{CDR} \text { ) (maximum }=5)^{30}$ using information from the neurologic, neuropsychological, and functional examinations. If subjects did not meet research criteria for dementia but showed some evidence of cognitive impairment, this was also rated. Subjects who had neuropsychological test scores close to the dementia cutoffs, or those who met test score but not functional impairment criteria, were considered to have questionable or borderline dementia and received a CDR score of 0.5 .

Clinical subtypes of dementia were defined for the purposes of this study ${ }^{31}$ based on temporal association between the dementia syndrome and stroke, if known, and correlations between clinical and neuropsychological features. Our goal in this subtyping was to determine if differences in syndromic profiles could be identified, but especially variations in longitudinal course and outcome based on inferred mechanisms. Alzheimer's disease with stroke $(\mathrm{AD}+\mathrm{CVA})$ was diagnosed when functional and memory impairments preceded the index stroke based on the best historical information. Stroke-related dementia (SRD) was defined as the new onset of dementia after a stroke whose location or size did not explain the observed global mental changes using traditional concepts of functional neuroanatomy. Dementia due to the focal effects of stroke (Focal) referred to profiles resulting from infarction(s) in a strategic location whose singular or additive effects appeared to account for the dementia syndrome. Other dementias (Other) encompassed clinical syndromes unrelated to stroke, such as alcohol dependency, severe depression, or psychosis. Diagnostic agreement at this level was also excellent with a kappa of 0.79 (sample of 63 patients as above).

Data analysis and statistics. The baseline cohort was defined as the sample of testable stroke patients who completed neuropsychological evaluations at 3 months.
Our incidence cohort is composed of patients who are nondemented at baseline and who will be followed over the course of the study. Since a proportion of the patients enrolled in the hospital did not complete 3-month evaluations $(n=46)$, we examined the features predicting examination status, using a multivariate logistic model, ${ }^{32}$ in order to assess selection biases. Among those examined and testable at baseline, rates of dementia as a percent were determined for each 5-year age interval. We further examined differences between stroke and control groups and between demented and nondemented stroke patients with respect to demographic features and performance on cognitive and functional examinations using univariate tests of association or unpaired $t$ test, as appropriate. In examining differences among the dementia subgroups, we used analysis of variance.

Crude odds ratios (ORs) estimating the risk of dementia in stroke subjects compared with the risk in control subjects were calculated for 10-year age intervals (60 to 69,70 to 79 , and $80+$ years). Although the stroke and control groups were closely matched by age, there were significant differences by sex, education, ethnicity, and primary language. To adjust for the effects of confounding by some of these demographic factors, a logistic regression model was developed using age, education, and race (white versus non-white) combined with subject status (stroke versus control) as independent variables. Sex and primary language were not included since they were not associated with dementia in the univariate analyses. The logistic procedure resulted in adjusted $\mathrm{ORs}$, with age-specific ratios derived from interaction terms (stroke by age). Other interactions (eg, age by race, education by race) were tested in a backward stepwise elimination procedure in separate analyses. In addition, we used a second method of adjustment to control for potential biases related to recruitment of hospitalized cases by confining the analysis to subjects (both patients and controls) residing in the Washington Heights-Inwood community of northern Manhattan defined by five zip code zones (10032, 10033, 10034, 10039, and 10040). This population-based approach has been suggested by Schlesselman ${ }^{33}$ to control for the bias of Berkson. ${ }^{34}$

Results. Differences between sample enrolled during hospitalization and cohort examined at the 3 month baseline. Among the 297 stroke subjects initially enrolled in the hospital, 251 (84.5\%) were examined and testable at 3 months (table 1) and constituted the baseline cohort. The difference was accounted for by 13 who died before 3 months, 14 with severe medical comorbidity or neurologic disability that prevented testing (in five patients, testing was attempted but was incomplete due to severe aphasia or pseudobulbar mutism), and 19 who either refused testing or emigrated from the New York City area. The 46 patients overall who were not examined or testable at 3 months did not differ from the remaining patients by age, sex, ethnicity, primary language, geographic origin, years of education, or prestroke BFAS score (table 2). The only features distinguishing those not examined compared with those examined were poorer performance on screening tests of cognitive function (MMSE and Short Blessed) and a greater degree of stroke disability (Barthel and Stroke Severity) assessed at 7 to 10 days following stroke. As 
Table 3. Characteristics distinguishing demented from nondemented stroke patients assessed at 3 months

\begin{tabular}{|c|c|c|c|}
\hline Characteristic & $\begin{array}{l}\text { Not demented } \\
\quad(\mathbf{n}=185)\end{array}$ & $\begin{array}{c}\text { Demented } \\
(\mathbf{n}=66)\end{array}$ & $p^{*}$ \\
\hline Age, mean (SD) & $70.3(7.7)$ & $76.7 \quad(9.1)$ & $<0.001$ \\
\hline \multicolumn{4}{|l|}{ Sex $(\%)$} \\
\hline Men & $89(78.1)$ & $25(21.9)$ & 0.152 \\
\hline Women & $96(70.1)$ & $41(29.9)$ & \\
\hline \multicolumn{4}{|l|}{ Ethnicity (\%) } \\
\hline White, non-Hispanic & $67(81.7)$ & $15(18.3)$ & 0.147 \\
\hline Black, non-Hispanic & $69(67.3)$ & $30(30.3)$ & \\
\hline Hispanic & $46(70.8)$ & $19(29.2)$ & \\
\hline \multicolumn{4}{|l|}{ Predominant language $(\%)$} \\
\hline English & $124(74.7)$ & $42(25.3)$ & 0.782 \\
\hline Spanish & $48(70.6)$ & $20(29.4)$ & \\
\hline Other & $13(76.5)$ & $4(23.5)$ & \\
\hline Residence ( $\%$ north Manhattan) & $75(68.8)$ & $34(31.2)$ & 0.123 \\
\hline Education, mean (SD) & $10.5 \quad(4.7)$ & $9.2(3.9)$ & 0.040 \\
\hline Short Blessed, mean (SD) & $5.3(5.6)$ & $14.3 \quad(8.3)$ & $<0.001$ \\
\hline MMSE, mean (SD) & $25.9 \quad(3.5)$ & $18.2(6.7)$ & $<0.001$ \\
\hline HDRS, mean (SD) & $4.7(4.5)$ & $6.1 \quad(5.0)$ & 0,040 \\
\hline BFAS, mean (SD) & $1.7 \quad(2.2)$ & $5.8(5.1)$ & $<0.001$ \\
\hline Barthel, mean (SD) & $88.4(19.9)$ & $66.9(34.2)$ & $<0.001$ \\
\hline Stroke Severity, mean (SD) & $4.6(3.1)$ & $7.1(2.9)$ & $<0.001$ \\
\hline \multicolumn{4}{|c|}{$\begin{array}{l}\text { Percentages indicate proportions between groups for each } \\
\text { characteristic. }\end{array}$} \\
\hline \multicolumn{4}{|c|}{$\begin{array}{l}\text { * } t \text { test for differences in means or chi-square for differences in } \\
\text { proportions. }\end{array}$} \\
\hline
\end{tabular}

Table 4. Age-specific risks of dementia after stroke given as crude and adjusted odds ratios, based on the frequency of dementia in stroke and control cohorts by decade

\begin{tabular}{|c|c|c|c|c|c|c|}
\hline \multirow{3}{*}{$\begin{array}{l}\text { Subject } \\
\text { groups }\end{array}$} & \multicolumn{6}{|c|}{ Dementia status of subjects } \\
\hline & \multicolumn{2}{|c|}{ Stroke } & \multicolumn{2}{|c|}{ Control } & \multicolumn{2}{|c|}{ Odds ratios } \\
\hline & Yes & No & Yes & No & Crude & Adjusted* \\
\hline $60-69$ & 17 & 98 & 2 & 120 & 10.4 & 6.4 \\
\hline $70-79$ & 26 & 66 & 1 & 95 & 37.4 & 31.2 \\
\hline $80+$ & 23 & 21 & 5 & 26 & 6.0 & 5.7 \\
\hline Total & 66 & 185 & 8 & 241 & 10.7 & 9.4 \\
\hline \multicolumn{7}{|c|}{$\begin{array}{l}\text { * Using logistic regression model with subject status (stroke versus } \\
\text { control) by age interaction, adjusting for effects of age, education, } \\
\text { and race for each age group (modification of Model A, table } 6 \text { ). }\end{array}$} \\
\hline
\end{tabular}

Dementia at baseline was also related to years of education $(31.4 \%$ for $\leq 8,29.5 \%$ for 9 to 12 , and $12.5 \%$ for $13+$ years) and to race $(29.9 \%$ for nonwhites versus $18.3 \%$ for whites) but not to sex or the predominant language spoken at home (table 3 ). Among 249 subjects in the control cohort, dementia was present in eight (3.2\%). Questionable or borderline dementia occurred in 19 of $251(7.6 \%)$ stroke patients and in 13 of $249(5.2 \%)$ control subjects.

Among stroke patients, those with dementia performed less well on mental function tests (Short Blessed, MMSE, and BFAS) compared with nondemented patients, as expected (table 3 ). In addition, those demented were significantly more impaired in activities of daily living and overall neurologic functions (Barthel Index and Stroke Severity Scale) and received a slightly higher score on the HDRS.
Table 5. Characteristics distinguishing stroke and control subjects

\begin{tabular}{|c|c|c|c|}
\hline Characteristic & $\begin{array}{l}\text { Stroke } \\
(\mathbf{n}=\mathbf{2 5 1})\end{array}$ & $\begin{array}{c}\text { Control } \\
(\mathbf{n}=249)\end{array}$ & $p^{*}$ \\
\hline Age, mean (SD) & $71.9(8.6)$ & $70.8(6.7)$ & 0.096 \\
\hline \multicolumn{4}{|l|}{$\operatorname{Sex}(\%)$} \\
\hline Men & $114(45.4)$ & $85(34.1)$ & \multirow[t]{2}{*}{0.010} \\
\hline Women & $137(54.6)$ & $164(65.9)$ & \\
\hline \multicolumn{4}{|l|}{ Ethnicity $(\%)$} \\
\hline White, non-Hispanic & $82(33.3)$ & $131(52,6)$ & \multirow[t]{3}{*}{$<0.001$} \\
\hline Black, non-Hispanic & $99(40.2)$ & $81(32.5)$ & \\
\hline Hispanic & $65(26.4)$ & $37(14.9)$ & \\
\hline \multicolumn{4}{|l|}{ Predominant language (\%) } \\
\hline English & $166(65.3)$ & $194(77.9)$ & \multirow[t]{3}{*}{0.001} \\
\hline Spanish & $68(27.8)$ & $37(14.9)$ & \\
\hline Other & $17 \quad(6.9)$ & $18(7.2)$ & \\
\hline Residence (\% north Manhattan) & $109(43.3)$ & $111(44.6)$ & 0.795 \\
\hline Education, mean (SD) & $10.1(4.5)$ & $12.3(4.6)$ & $<0.001$ \\
\hline Short Blessed, mean (SD) & $7.6(7.5)$ & 3.2 & $<0.001$ \\
\hline MMSE, mean (SD) & $24.0(5.6)$ & 27.9 & $<0.001$ \\
\hline HDRS, mean (SD) & $5.0(4.7)$ & $3.5(4.0)$ & $<0.001$ \\
\hline BFAS, mean (SD) & $2.8(3.7)$ & $0.3 \quad(0.5)$ & $<0.001$ \\
\hline Barthel, mean (SD) & $82.0(26.0)$ & 99.7 (1.7) & $<0.001$ \\
\hline Stroke Severity, mean (SD) & $5.3(3.3)$ & 0.6 & $<0.001$ \\
\hline CDR, mean $(\mathrm{SD})$ & $0.4(0.8)$ & $0.1(0.2)$ & $<0.001$ \\
\hline \multicolumn{4}{|c|}{ Percentages indicate proportions within each subject group. } \\
\hline \multicolumn{4}{|c|}{$\begin{array}{l}* t \text { test for differences in means or chi-square for differences in } \\
\text { proportions. }\end{array}$} \\
\hline
\end{tabular}

These results are briefly presented here in order to describe baseline features of our cohort; more detailed analyses of these variables are planned in future studies.

Risk of dementia estimated by logistic model. The odds of having dementia after stroke compared with the odds in the stroke-free control sample are shown as a crude OR in table 4 for each 10-year age interval. Overall, the unadjusted OR was 10.7 . However, in comparing the stroke and control cohorts, differences in demographic characteristics were evident (table 5), potentially confounding the estimation of dementia risk. Since we were unable to control for all of these factors at the recruitment phase, we used a logistic model to adjust for age (60 to 69,70 to $79,80+$ years), education $(\leq 8,9$ to 12 , $13+$ years), and race (non-white versus white) with dementia as the dependent variable for both stroke and control subjects combined (total $=495$, excluding five whose race was classified as "other"). The overall adjusted OR was 9.4 (table 6, model A), with a range of 4.2 to 21.1 (95\% confidence interval [CI]). With the youngest subjects (60 to 69 years) serving as the reference group for age-specific comparisons, the OR by age groups in table 6 may be interpreted as follows: a subject (stroke or control) 80 years or older has a risk of dementia 10.7 times the risk for a subject 60 to 69 years. Similarly, with college-educated subjects $(13+$ years) serving as the reference group for education-specific comparisons, those with $\leq 8$ years of education have a risk that is 4.3 times in excess. For race, the OR was marginal in significance with a 1.8 times risk of 
Table 6. Independent correlates of dementia using multiple logistic model for the sample overall (Model A) and the community-based subgroup from northern Manhattan (Model B)

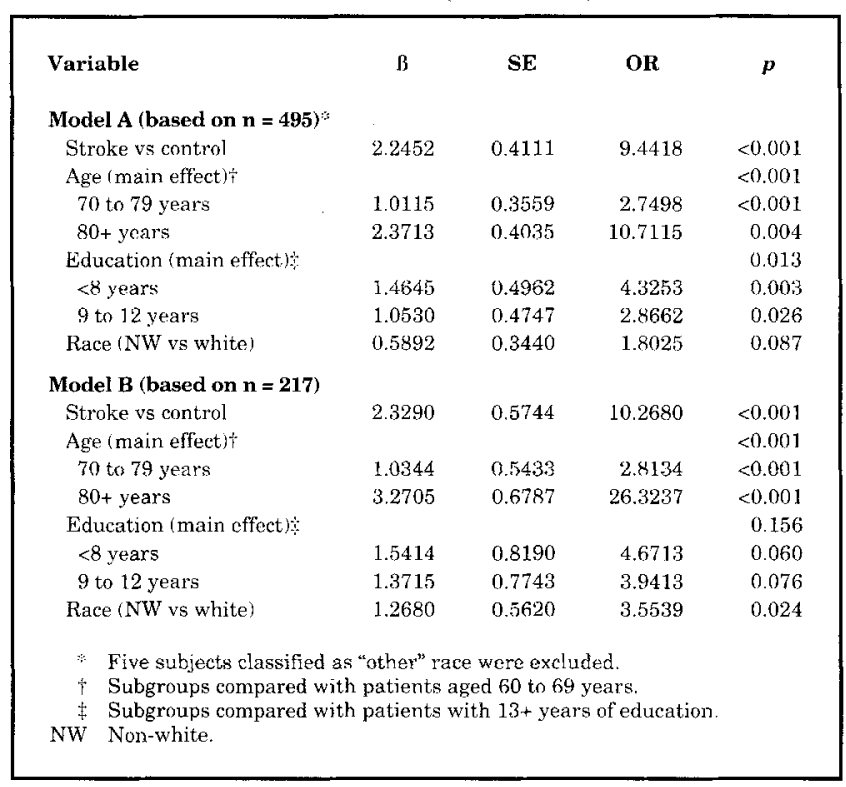

dementia for a non-white subject compared with a white subject.

In further refining this adjustment procedure, we confined the analysis to stroke and control subjects (total $=217$, excluding three whose race was classified as "other") residing in the five zip code zones of the Washington Heights-Inwood community. Among the 109 stroke subjects from the community, $31.2 \%$ were demented. In contrast, among 111 control subjects, $4.5 \%$ were demented. The logistic model using this population-based sample resulted in an overall adjusted OR of 10.3 (3.3 to $32.3,95 \%$ CI) as the risk of dementia after stroke (table 6 , model B), similar to that for the overall sample. However, compared with model A, two differences are notable: the dementia risk of the oldest age group in the community subsample was higher (OR $=26.3$ versus 10.7 ), and the effect of race was significant and substantial $(\mathrm{OR}=3.6)$.

By adding an interaction term for age (ie, subject status by age) to model $\mathrm{A}$, we derived age-specific ORs for stroke compared with control subjects, adjusting for age, education, and race for each age group (table 4). Although this interaction was not significant, the trend in ORs by decade of age is informative. The highest $\mathrm{OR}$ applied to the 70 to 79 group, while the OR declined for those $80+$ years. This effect occurred because the stroke risk was examined in relation to the control risk by age; among elderly controls, the proportion with dementia increased (eg, five cases of dementia, all diagnosed as AD) as expected in a community reference sample, thereby diminishing the dementia risk from stroke in the very elderly. Thus, stroke has a larger impact on dementia in younger age groups. Finally, other interactions were tested, but none proved significant.
Table 7. Clinical features of dementia subtypes in stroke cohort

\begin{tabular}{|c|c|c|c|c|c|}
\hline \multirow[b]{2}{*}{ Characteristic } & \multicolumn{5}{|c|}{ Dementia subtypes } \\
\hline & $\begin{array}{l}\mathbf{A D}+\mathrm{CVA} \\
(\mathrm{n}=24)\end{array}$ & $\begin{array}{c}\text { SRD } \\
(\mathbf{n}=\mathbf{2 0})\end{array}$ & $\begin{array}{c}\text { Focal } \\
(\mathbf{n}=17)\end{array}$ & $\begin{array}{l}\text { Other } \\
(\mathbf{n}=\mathbf{5})\end{array}$ & $p$ \\
\hline Age & $82.3(7.5)$ & $74.8(9.2)$ & $73.8(6.3)$ & $67.0\{6.9\}$ & $<0.001$ \\
\hline $\operatorname{Sex}(\%$ men $)$ & 29.2 & 45.0 & 29.4 & 80.0 & 0.139 \\
\hline Race (\% non-white) & 87.5 & 79.0 & 50.0 & 100.0 & 0.025 \\
\hline Education & $9.4(4.0)$ & $9.2(4.1)$ & $9.4(3.9)$ & $6.8(2.4)$ & 0.574 \\
\hline Short Blessed & $16.8(9.8)$ & $10.4(6.5)$ & $16.1(7.5)$ & $13.7(4.9)$ & 0.066 \\
\hline MMSE & $15.8(7.7)$ & $20.9(4.4)$ & $17.7(7.2)$ & $19.4(4.5)$ & 0.099 \\
\hline HDRS & $6.7(5.4)$ & $4.2(3.6)$ & $7.4(5.7)$ & $8.5(5.6)$ & 0.162 \\
\hline BFAS & $8.4(5.5)$ & $3.8(3.8)$ & $5.5(5.0)$ & $4.6(5.5)$ & 0.030 \\
\hline Barthel Index & $48.1(35.7)$ & $84.2(20.7)$ & $67.6(36.1)$ & $76.2(31.4)$ & 0.006 \\
\hline Stroke Severity & $8.5(2.0)$ & $5.4(3.2)$ & $7.7(2.5)$ & $6.2(4.0)$ & 0.005 \\
\hline \multicolumn{6}{|c|}{ Values are mean (SD) except where indicated. } \\
\hline \multicolumn{6}{|c|}{$\begin{array}{l}\text { Chi-square for proportions or ANOVA for means comparing dementia } \\
\text { subgroups, AD+CVA differs from all otherst or from SRDt at } p<0.05 \\
\text { (Scheffe). }\end{array}$} \\
\hline
\end{tabular}

Dementia subtypes and their characteristics. We recognized three major dementia subtypes (AD + CVA, SRD, and Focal) which were about equally proportioned. Patients with $A D+C V A$ constituted $36.4 \%$ of the demented sample. Compared with the other groups, they were more advanced in age, more often non-white, and appeared to show the greatest degree of functional and cognitive impairments, reflected in the Short Blessed, MMSE, Barthel, and Stroke Severity scores (table 7). The two groups in whom vascular disease was inferred to be the central mechanism (SRD and Focal) constituted $56.1 \%$ of the demented sample overall. No significant differences were evident between them although the Focal group appeared to perform less well on the MMSE and had more severe stroke disability.

We did not consider these subtypes individually when estimating the risks of dementia associated with stroke because this was not relevant to the central question posed at the beginning. However, in order to allow comparisons with other studies using the more conventional DSM-III-R criteria for multi-infarct dementia (MID), it is possible to recalculate the baseline frequency of dementia presumably related to cerebrovascular disease alone. If the 24 patients with $\mathrm{AD}+\mathrm{CVA}$ and five patients with Other dementias (total $=29$ ) are excluded from the sample, this would leave 37 patients with dementia directly related to vascular disease (SRD and Focal). The baseline frequency of dementia would then be $16.3 \%$ (37 of 227 total stroke patients). Unlike most studies of cerebrovascular dementia, we did not rate patients with Hachinski's Ischemic Score ${ }^{38}$ in our diagnostic algorithm, in part because its use does not assist in the clinical discrimination between mixed dementias (eg, AD+CVA) and "pure" vascular dementias. ${ }^{39}$ Nonetheless, some of our demented patients would have a high ischemic score (especially patients in the Focal group), thus qualifying for the diagnosis of MID. In interpreting these proportions, the recalculated baseline frequency might be consid- 
ered to reflect the minimum risk of dementia from stroke, while the overall frequency of $26.3 \%$ includes the combined risks of cerebrovascular disease and aging.

Discussion. The neuropsychological consequences of cerebrovascular disease are measurable and significant. Dementia was present in approximately one fourth of our patients surviving 3 months after ischemic stroke. Among those with dementia, stroke was the underlying cause in slightly more than one half, while stroke complicating $\mathrm{AD}$ was the presumed cause in about one third. Compared with a stroke-free sample, the risk of having dementia following stroke was at least nine times greater, after adjusting for age, years of education, and race, each of which also contributed independently to this risk. Thus, we conclude that the occurrence of cerebrovascular disease significantly adds to the baseline risk of dementia expected with advancing age.

Our study is the first to provide a quantitative estimate of both the frequency and risk of dementia associated with ischemic stroke. In an exploratory effort, we previously found that dementia was present in $15.9 \%$ of patients in the SDB cohort aged $\geq 60$ years who were assessable 7 to 10 days following ischemic stroke. ${ }^{40}$ Since the SDB was not intended to study dementia, the diagnosis depended on clinical judgment alone without explicit criteria or supporting mental function tests, a recognized deficiency of the study. Moreover, disorders of attention and arousal in the subacute phase of stroke might have confounded the interpretation of mental changes, ${ }^{41}$ even though only testable patients were included in the frequency estimate. In the present study, we used neuropsychological testing combined with well-defined diagnostic criteria that were applied with a high degree of reliability. In addition, we defined baseline frequency based on observations made 3 months after stroke onset in order to allow the acute effects of stroke to subside. If patients were too aphasic or met criteria for delirium even 3 months after onset, they were considered untestable and not included in the baseline sample. Using these methods, the frequency of dementia was higher than we previously reported. These methods will also permit us to take an analytic approach in examining the role of vascular and stroke factors as well as the longitudinal course of neuropsychological deficits after stroke.

The validity of our risk estimates could be challenged because of potential biases related to study design issues inherent in any case-control approach $^{33}$ and because of problems specific to clinical studies of cerebrovascular dementia. First, in studying hospitalized patients, we risked introducing Berkson's bias, ${ }^{34}$ leading to an overestimation of the stroke risk if differential hospitalization occurred because of dementia. However, we believe that this potential bias was minimal because patients with acute cerebrovascular disease gener- ally have been admitted nonselectively to our medical center, without regard to coexisting disease (including dementia). Rather, comorbidity usually determined the specific clinical service responsible for the patient's primary care. In fact, it could be argued that cerebrovascular events might be overlooked in patients with preexisting dementia, reducing the probability of hospitalization. Most importantly, the subgroup analysis using the community sample defined by geographic origin demonstrated a significant and comparable elevation of the OR. Our choice of hospitalized patients ensured that we enrolled a well-defined, consecutive stroke cohort whose onset features and course could be fully characterized, thus optimizing case detection and followup, which otherwise might have been sources of bias. All subjects were personally examined by the neurologic team in both the acute and chronic phases of the stroke. Second, the choice of community controls, most of whom were either spouses or randomly selected, was a deliberate effort to obtain baseline rates of dementia in a stroke-free sample that would have a risk for cerebrovascular disease comparable with the patients. Since this was incompletely controlled at the selection phase (the "healthy volunteer" effect), we adjusted for confounding statistically by using a logistic model, taking into account age, education, and ethnicity, factors that were related to both the disease (dementia) and exposure (stroke) of interest. Third, the diagnosis of dementia from cerebrovascular disease is problematic. ${ }^{31}$ In this effort, we used a diagnostic algorithm based on traditional criteria combined with conservative cutoff scores on neuropsychological tests ${ }^{14}$ that were uniformly applied but flexible enough to take into account the effects of focal brain injury. In addition, an effort was made to distinguish between those with preexisting cognitive impairments consistent with $\mathrm{AD}$ and those with cognitive deterioration following stroke onset using the best available clinical information, although we recognize that pathologic verification would be needed to maximize diagnostic accuracy.

Despite these potential biases, we believe our findings are not only valid but also consistent with the few uncontrolled studies of diverse and smaller stroke samples from which crude estimates of dementia frequency can be derived. Eastwood et $\mathrm{al}^{42}$ examined 60 patients (mean age $=82$ years) dwelling in the community and in nursing homes, of whom 12 were found to have stroke. Based on performance on screening cognitive tests, three (25.0\%) were judged to have mild to moderate cognitive impairment. Hershey at al $^{43}$ studied 34 patients (mean age $=63$ years) who were selected from a drug trial of stroke recurrence. Using DSMIII criteria and performance on a screening cognitive examination, dementia was found in eight $(23.5 \%)$ patients, while another eight $(23.5 \%)$ were considered borderline. Babikian et $\mathrm{al}^{44}$ prospectively examined 23 men (mean age $=63$ years) who met clinical and CT criteria for multiple cerebral 
infarctions, selected from 203 patients seen in the hospital or clinic. Applying the standard MMSE cutoff score of $<24$ points, they classified seven patients $(30.4 \%)$ as demented. Ladurner et $\mathrm{al}^{45}$ examined 71 hospitalized patients (mean age $=57$ years) with ischemic stroke whose criteria for selection were not specified. Based on performance on the WAIS, 40 patients $(56.3 \%)$ were found to have dementia.

Similar to the observations in $\mathrm{AD}$, dementia associated with cerebrovascular disease was strongly age-related, a relationship that was nonlinear. The extent of formal education was also a predictor of dementia, as has been found recently in population studies of $\mathrm{AD} .{ }^{46}$ Whether this is an artefact of our testing methods or a true risk factor is a subject of further investigation. ${ }^{14,15}$ Racial group, even when controlled for education and age, was weakly associated with dementia in the sample overall but was a significant independent predictor $(\mathrm{OR}=3.6)$ when confining the analysis to the community sample from the Washington HeightsInwood section of northern Manhattan. This subsample includes a larger proportion of blacks and Hispanics than the overall group. It remains to be determined if race is an independent risk factor when considered in relationship to vascular risks and stroke features. Studies of dementia in nonwhite populations in the Far East have demonstrated that vascular dementia exceeds the frequency of $\mathrm{AD}$ (a reversal of the proportion commonly seen in North American and European populations), ${ }^{47}$ consistent with the view that vascular factors may play a role in dementia.

If the baseline frequency of dementia in our elderly stroke cohort is generalizable, there may be as many as 431,530 persons with stroke and dementia in the United States, taking $26.3 \%$ of the approximately $1,640,800$ survivors of ischemic stroke $\geq 60$ years of age estimated from the most recent statistics from the American Heart Association. ${ }^{48}$ (Those statistics indicate that the overall prevalence of stroke was 2,930,000 in 1988, of which we estimate $80 \%$ or $2,344,000$ would be due to ischemic stroke. Assuming $70 \%$ of patients with ischemic stroke were $\geq 60$ years of age, the estimated prevalence would be $1,640,800$.) If we take the frequency of $16.3 \%$ (representing stroke effects alone), the projected number would be 267,450 . The latter figure is close to the estimate of vascular dementia calculated by Brust, ${ }^{49}$ who extrapolated from proportions found in autopsy data (250,000 persons). Whether we take the upper or lower limit as the true frequency, it is clear that dementia associated with stroke affects large numbers of elderly persons in the United States. Finally, when viewed in relation to the risk of other exposures such as head trauma (OR $=2.0$ to 5.3$),{ }^{50}$ the risk of dementia with stroke $(\mathrm{OR}=9.4$ to 10.3 , depending on the sample examined) is considerable, with important public health implications for our rapidly aging population.

\section{Acknowledgments}

The authors are indebted to Ms. Mindy Bart-Pirro, who adroitly managed the database, and the staff of the Stroke and Aging Research Project for their dedicated efforts. We also thank Drs. Ann Camac and Albert Favate for their assistance in the neurologic assessment of patients.

\section{References}

1. Brust JCM. Vascular dementia is overdiagnosed. Arch Neurol 1988;45:799-801.

2. O'Brien MD. Vascular dementia is underdiagnosed. Arch Neurol 1988;45:797-798.

3. Tomlinson BE, Blessed G, Roth $\mathbf{M}$. Observations on the brains of demented old people. J Neurol Sci 1970;11:205-242.

4. Katzman R. Vascular disease and dementia. In: Yahr MD, ed. H. Houston Merritt memorial volume. New York: Raven Press, 1983:153-176.

5. Schoenberg BS, Anderson DW, Haerer AF. Severe dementia: prevalence and clinical features in a biracial US population. Arch Neurol 1985;42:740-742.

6. Kase CS, Wolf PA, Bachman DL, Linn RT, Cupples LA. Dementia and stroke: the Framingham study. In: Ginsberg MD, Dietrich WD, eds. Cerebrovascular diseases. 16th Research (Princeton) Conference. New York: Raven Press, 1989:193-198.

7. Katzman R, Lasker B, Bernstein N. Advances in the diagnosis of dementia: accuracy of diagnosis and consequences of misdiagnosis of disorders causing dementia. In: Terry RD, ed. Aging and the brain. New York: Raven Press, 1988:17-62.

8. Goodglass H, Kaplan E. The assessment of aphasia and related disorders, 2nd ed. Philadelphia: Lea \& Febiger, 1983.

9. Foulkes MA, Wolf PA, Price TR, Mohr JP, Hier DB. The Stroke Data Bank: design, methods, and baseline characteristics. Stroke 1988;19:547-554.

10. Folstein MF, Folstein SE, McHugh PR. Mini-mental state: a practical method for grading the cognitive state of patients for the clinician. J Psychiatr Res 1975;12:189-198.

11. Mahoney FI, Barthel DW. Functional evaluation: Barthel index. Md State Med J 1965;14:61-65.

12. Blessed $\mathrm{G}$, Tomlinson $\mathbf{B E}$, Roth $\mathrm{M}$. The association between quantitative measures of dementia and of senile change in the cerebral grey matter of elderly subjects. Br J Psychiatry $1968 ; 114: 797-811$.

13. Katzman R, Brown T, Fuld P, Peck A, Schecter R, Schimmel $\mathrm{H}$. Validation of a short orientation-memory-concentration test of cognitive impairment. Am J Psychiatry 1983;140:734739.

14. Stern Y, Andrews H, Pittman J, et al. Diagnosis of dementia in a heterogeneous population. Development of a neuropsychological paradigm-based diagnosis of dementia and quantified correction for the effects of education. Arch Neurol 1992;49:453-460.

15. Pittman J, Andrews H, Tatemichi T, et al. Diagnosis of dementia in a heterogeneous population. A comparison of paradigm-based diagnosis and physician's diagnosis. Arch Neurol 1992;49:461-467.

16. Skilbeck CE, Wade DT, Hewer RL, Wood VA. Recovery after stroke. J Neurol Neurosurg Psychiatry 1983;46:5-8.

17. Wade DT, Wood VA, Newer RL. Recovery after stroke-the first 3 months. J Neurol Neurosurg Psychiatry 1985;48:7-13.

18. Bushke H, Fuld PA. Evaluating storage, retention, and retrieval in disordered memory and learning. Neurology 1974;24:1019-1025.

19. Benton AL. The visual retention test. New York: The Psychological Corporation, 1955.

20. Kaplan E, Goodglass H, Weintraub S. Boston naming test. Philadelphia: Lea \& Febiger, 1983.

21. Benton A. FAS test. In: Spreen O, Benton A, eds. Neurosensory center comprehensive examination for aphasia. Victoria, BC: University of Victoria, 1967.

22. Rosen W. The Rosen drawing test. Bronx, NY: Veterans 
Administration Medical Center, 1983.

23. Wechsler D. Wechsler adult intelligence scale--revised. New York: The Psychological Corporation, 1981.

24. Mattis S. Mental status examination for organic mental syndrome in the elderly patient. In: Bellak L, Karasu TB, eds. Geriatric psychiatry. New York: Grune \& Stratton, 1976.

25. Sano M, Rosen W, Mayeux R. Attention deficits in Alzheimer's disease. Presented at the 92nd annual meeting of the American Psychological Association, Toronto, Canada, August 1984.

26. Williams JBW. A structured interview guide for the Hamilton Depression Rating Scale. Arch Gen Psychiatry 1988;45:742-747.

27. Spitzer RL, Williams JBW, Gibbon M, First MB. The structured clinical interview for DSM-III-R (SCID). I. History, rationale and description. Arch Gen Psychiatry (in press).

28. American Psychiatric Association. Diagnostic and statistical manual of mental disorders, 3rd ed, revised. Washington, DC: American Psychiatric Association, 1987.

29. Fleiss JL. Statistical methods for rates and proportions. New York: John Wiley \& Sons, 1981.

30. Hughes CP, Berg L, Danziger WL, Cohen LA, Martin RL. A new clinical scale for the staging of dementia. Br J Psychiatry 1982;140:566-572.

31. Tatemichi TK. How acute brain failure becomes chronic: a view of the mechanisms of dementia related to stroke. Neurology 1990;40:1652-1659.

32. Walker SH, Duncan DB. Estimation of the probability of an event as a function of several independent variables. Biometrika 1967;54:167-179.

33. Schlesselman JJ. Case-control studies. Design, conduct, analysis. New York: Oxford University Press, 1982.

34. Berkson J. Limitations of the application of fourfold tables to hospital data. Biometries Bull 1946;2:47-53.

35. Tatemichi TK, Desmond DW, Paik M, et al. The mini-mental state examination as a screen for dementia following stroke [abstract]. J Clin Exp Neuropsychol 1991;13:419.

36. Wade DT, Skilbeck C, Hewer RL. Selected cognitive losses after stroke. Int Disabil Stud 1989;11:34-39.

37. Prescott JR, Garraway WM, Akhtar AJ. Predicting functional outcome following acute stroke using a standard clinical examination. Stroke 1982;13:641-647.

38. Rosen WG, Terry RD, Fuld PA, Katzman R, Peck A. Pathologic verification of ischemic score differentiation of dementias. Ann Neurol 1979;7:486-488.

39. Molgaard CA. Multivariate analysis of Hachinski's scale for discriminating senile dementias of the Alzheimer's type from multi-infarct dementia. Neuroepidemiology 1987;48:1085-1090.

40. Tatemichi TK, Foulkes MA, Mohr JP, et al. Dementia in stroke survivors in the Stroke Data Bank cohort: prevalence, incidence, risk factors and computed tomographic findings. Stroke 1990;21:858-866.

41. Hijdra A, Derix MMA, Teunisse S, van Gool WA, Kwa IH. Dementia after stroke [letter]. Stroke 1991;22:416,

42. Eastwood MR, Lautenschlaeger E, Corbin S. A comparison of clinical methods for assessing dementia. J Am Geriatr Soc 1983;31:342-347.

43. Hershey LA, Modic MT, Greenough PG, Jaffe DF. Magnetic resonance imaging in vascular dementia. Neurology 1987;37:29-36.

44. Babikian VL, Wolfe N, Linn R, Knoefel JE, Albert ML Cognitive changes in patients with multiple cerebral infarcts. Stroke 1990;21:1013-1018.

45. Ladurner G, Iliff LD, Lechner H. Clinical factors associated with dementia in ischaemic stroke. J Neurol Neurosurg Psychiatry 1982;45:97-101.

46. Zhang M, Katzman $R$, Salmon $D$, et al. The prevalence of dementia and Alzheimer's disease in Shanghai, China: impact of age, gender, and education. Ann Neurol 1990;27:428-437.

47. Hasegawa K, Homma A, Imai Y. An epidemiological study of age-related dementia in the community. Int $\mathrm{J}$ Geriatr Psychiatry 1986;1:45-55.

48. American Heart Association. Fact sheet on heart attack, stroke, and risk factors. Dallas, TX, 1988.

49. Brust JCM. Dementia and cerebrovascular disease. In: Mayeux R, Rosen WG, eds. The dementias. New York: Raven Press, 1983:131-147.

50. Rocca WA, Amaducci LA, Schoenberg BS. Epidemiology of clinically diagnosed Alzheimer's disease. Ann Neurol 1986;19:415-424. 


\section{Neurology}

\section{Dementia after stroke: Baseline frequency, risks, and clinical features in a hospitalized cohort}

T. K. Tatemichi, D. W. Desmond, R. Mayeux, et al.

Neurology 1992;42;1185

DOI 10.1212/WNL.42.6.1185

\section{This information is current as of June 1, 1992}

\section{Updated Information \&}

Services

\section{Citations}

Permissions \& Licensing

Reprints including high resolution figures, can be found at: http://n.neurology.org/content/42/6/1185.full

This article has been cited by 58 HighWire-hosted articles: http://n.neurology.org/content/42/6/1185.full\#\#otherarticles

Information about reproducing this article in parts (figures,tables) or in its entirety can be found online at:

http://www.neurology.org/about/about_the_journal\#permissions

Information about ordering reprints can be found online:

http://n.neurology.org/subscribers/advertise

Neurology ${ }^{\circledR}$ is the official journal of the American Academy of Neurology. Published continuously since 1951, it is now a weekly with 48 issues per year. Copyright (C) 1992 by AAN Enterprises, Inc.. All rights reserved. Print ISSN: 0028-3878. Online ISSN: 1526-632X.

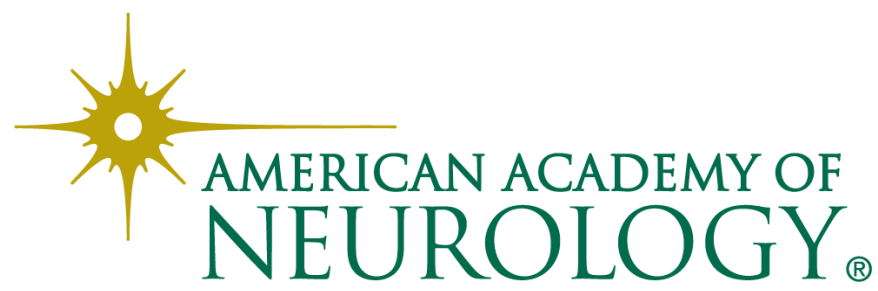

